Vol. 1 No. 2, Juni 2021, hlm. $187-194$

DOI: https://doi.org/10.33330/jutsi.v2i1.1179

Available online at http://jurnal.stmikroyal.ac.id/index.php/jutsi

\title{
IMPLEMENTASI ALGORITMA MOORA UNTUK PEMILIHAN BIBIT CABAI UNGGUL DI KOTA TANJUNGBALAI BERBASIS WEB
}

\author{
Imam Wahyudi ${ }^{1}$, Wan Mariatul Kifti ${ }^{2}$, Sudarmin ${ }^{2}$ \\ ${ }^{1}$ Mahasiswa Prodi Sistem Informasi, STMIK Royal \\ ${ }^{2}$ Prodi Sistem Informasi, STMIK Royal \\ *email : kifti.inti@gmail.com
}

\begin{abstract}
Abstrack:Chili is one type of plant that is widely planted by the community. Chili becomes a vegetable that has high economic value. However, farmers still use traditional methods in determining the chili seeds to be planted. Just as farmers choose chili seeds based only on chili seeds at a low price, so it is less able to overcome various pests that allow yields to fall. Of course this will have an impact on the lack of sale prices of crops. to carry out a research process by applying technology that can increase the yield of chilli crops through the application of a Decision Support System. The method used is the MOORA method which is one of the methods of a decision support system. Through the application of this method, researchers will compare each type of chilli seedlings based on criteria that will determine which chili is said to be superior. So that it will produce an information about the types of superior chili seeds based on all the existing criteria. Through the creation of a web-based system / application for the selection of superior chilli seedlings, farmers in Indonesia have broad access to take advantage of the results of future research making it easier for farmers to know which chili seeds are superior.The results of this study obtained the most superior chili with the highest value of 0.469 , namely large red chilies. So what is the result of the recommendation for the implementation of this MOORA method is large red chili.
\end{abstract}

Keywords:Decision Support System; MOORA Method; Chili Seed

\begin{abstract}
Abstrak: Cabai merupakan salah satu jenis tanaman yang banyak ditanam masyarakat. Cabai menjadi sayuran yang memiliki nilai ekonomis yang tinggi. Akan tetapi petani masih menggunakan cara tradisional dalam menentukan bibit cabai yang akan ditanam. Seperti halnya petani memilih bibit cabai hanya berdasarkan bibit cabai dengan harga yang murah, sehingga hal tersebut kurang mampu mengatasi berbagai hama yang memungkinkan hasil panen menjadi turun. Tentu hal tersebut akan berdampak pada kurangnya harga jual hasil panen. untuk melakukan proses penelitian dengan menerapkan teknologi yang dapat meningkatkan hasil panen tanaman cabai melalui penerapan Sistem Pendukung Keputusan. Metode yang digunakan adalah metode MOORA yang merupakan salah satu metode dari sistem pendukung keputusan. Melalui penerapan metode ini, peneliti akan membandingkan setiap jenis bibit cabai berdasarkan kriteria yang akan menentukan suatu cabai dikatakan unggul. Sehingga hal tersebut akan menghasilkan sebuah informasi tentang jenis bibit cabai unggul berdasarkan semua kriteria yang ada. Melalui pembuatan sistem/aplikasi berbasis web untuk pemilihan bibit cabai unggul ini, maka para petani di Indonesia memiliki akses luas untuk memanfaatkan hasil penelitian nantinya sehingga memudahkan para petani mengetahui bibit cabai yang unggul. Hasil dari penelitian ini mendapatkan hasil cabai yang paling unggul dengan nilai tertinggi 0,469 yaitu cabai merah besar.
\end{abstract}

Kata Kunci:Sistem Pendukung Keputusan; Metode MOORA;Bibit Cabai 
Vol. 1 No. 2, Juni 2021, hlm. $187-194$

DOI: https://doi.org/10.33330/jutsi.v2i1.1179

Available online at http://jurnal.stmikroyal.ac.id/index.php/jutsi

\section{PENDAHULUAN}

Cabai merupakan salah satu jenis tanaman yang banyak ditanam masyarakat. Cabai menjadi sayuran yang memiliki nilai ekonomis yang tinggi [1]. Peranan cabai yang sangat diminati sebagai salah satu bahan makanan membuat petani lebih keras untuk meningkatkan produktivitas cabai. Berdasarkan data BPS tahun 2019, produksi cabai rawit mencapai 1,34 ton pertahun. Hal ini menunjang para petani untuk menghasilkan hasil panen cabai dengan kuantitas dan kualitas yang optimal.

Selama ini para petani dalam menentukan bibit cabai unggul menggunakan konsep manual atau tradisional yang bersifat subyektif seperti melakukan cara coba-coba dalam menentukan bibit cabai yang akan ditanam. Alhasil tanaman yang terjadi adalah hasil panen yang kurang maksimal dan cenderung menurun bahkan hal yang tidak diinginkan yaitu mengalami sebuah gagal panen.

Sama halnya yang terjadi di Desa Sei Tualang Raso Kota Tanjungbalai yang men-jadi lokasi penelitian, petani masih menggunakan cara tradisional dalam menentukan bibit cabai yang akan ditanam. Seperti halnya petani memilih bibit cabai hanya ber-dasarkan bibit cabai dengan harga yang murah, sehingga hal tersebut kurang mampu mengatasi berbagai hama yang memungkinkan hasil panen menjadi turun. Selain itu, tonase yang lebih sedikit hal itu juga berpengaruh pada kualitas cabai yang akan dihasil-kan, tentu hal tersebut akan berdampak padakurangnya harga jual hasil panen.

Sistem pendukung membantu pengambilan keputusan manajemen dengan mengg-abungkan data, model-model dan alat-alat analisis yang komplek, serta perangkat lunak yang akrab dengan tampilan pengguna ke dalam satu sistem yang memiliki kekuatan besar (powerfull) yang dapat mendukung pengambilan keputusan yang semi atau tidak terstruktur.

Berdasarkan uraian permasalahan di atas, penulis tertarik untuk melakukan proses penelitian dengan menerapkan teknologi yang dapat meningkatkan hasil panen tanaman cabai melalui penerapan Sistem Pendukung Keputusan. Metode yang digunakan adalah Metode MOORA yaitu sistem yang mengoptimalkan dua atau lebih atribut yang saling bertentangan secara bersamaan. Metode ini diterapkan untuk mencari solusi dengan model matematika yang kompleks [2]. Peneliti akan membandingkan setiap jenis bibit cabai berdasarkan kriteria yang akan menentukan suatu cabai dikatakan unggul. Sehingga hal tersebut akan menghasilkan sebuah informasi tentang jenis bibit cabai unggul berdasarkan semua kriteria yang ada. Dengan memanfaatkan hasil penelitian nantinya sehingga memudah-kan para petani mengetahui bibit cabai yang unggul.

\section{METODE}

Sistem pendukung keputusan menyajikan kepada pengguna satu perangkat alat yang fleksibel dan memiliki kemampuan tinggi untuk analisis data penting. Dengan kata lain, sistem pendukung keputusan menggabungkan sumber daya intelektual seorang individu dengan kemampuan komputer dalam rangka meningkatkan kualitas pengambilan keputusan [3]. Pada metode ini memilki lima tahapan yang harus diikuti: 
Vol. 1 No. 2, Juni 2021, hlm. $187-194$

DOI: https://doi.org/10.33330/jutsi.v2i1.1179

Available online at http://jurnal.stmikroyal.ac.id/index.php/jutsi

(1)Memiliki tujuan yang jelas dan atribut evaluasi yang akan diidentifikasi., (2) Memunculkan semua kriteria yang ada dalam penelitian berbentuk matriks keputusan. $\mathrm{X}$ merupakan nilai atribut pada setiap atribut, yang diperesentasikan dalam bentuk perkalian sebagai berikut [4]:

$$
\mathbf{X}=\left[\begin{array}{lll}
\mathrm{X}_{11} & \mathrm{X}_{12} & \mathrm{X}_{1 \mathrm{n}} \\
\mathrm{X}_{21} & \mathrm{X}_{22} & \mathrm{X}_{2 \mathrm{n}} \\
\mathrm{X}_{\mathrm{m}} & \mathrm{X}_{\mathrm{m}} & \mathrm{X}_{\mathrm{mn}}
\end{array}\right]
$$

Membuat kesimpulan tentang denominator, yang merupakan pilihan terbaik dari penjumlahan kuadrat dari akar kuadran pada setiap atribut. Rumusnya adalah:

$$
X_{i j}=\frac{X_{i j}}{\sqrt{\sum_{j=1}^{m} X_{i j}^{2}}}
$$

Keterangan:

Rasio $\mathrm{X}_{\mathrm{ij}}=$ alternatif ke 1 pada kriteria ke $\mathrm{j}$,

$\mathrm{m} \quad=$ jumlah alternative,

$\mathrm{n} \quad=$ jumlah kriteria [5].

Penghitungan optimalisasi sebagai berikut:

$$
Y_{i}=\sum_{j=1}^{g} X_{i j} \sum_{j=g+1}^{n} X_{i j}
$$

Keterangan:

g = nilai atribut yang dimaksimalkan,

$(\mathrm{n}-\mathrm{g}) \quad=$ nilai atribut yang diminimalkan,

$\mathrm{Yi}=$ nilai normalisasi alternatif $\mathrm{i}$ semua atribut.

Atribut-atribut penting itu diberi bobot yang sesuai (signifikan koefisien). Jika bobot atribut penting ini dipertimbangkan, maka rumus Yi sebagai berikut:

$$
Y_{i}=\sum_{j=1}^{g} W_{j} X_{i j} \sum_{j=g+1}^{n} W_{j} X_{i j}
$$

Keterangan:

$\mathrm{Wj}=$ bobot atribut $\mathrm{j}$.

$\mathrm{Yi}=$ bisa bernilai positif atau negatif, bergantung pada jumlah maksimal kriteria benefit dan minimal kriteria cost pada perkalian keputusan (matriks). 
Vol. 1 No. 2, Juni 2021, hlm. $187-194$

DOI: https://doi.org/10.33330/jutsi.v2i1.1179

Available online at http://jurnal.stmikroyal.ac.id/index.php/jutsi

\section{HASIL DAN PEMBAHASAN}

Pada pembahasan dalam penelitian ini, maka akan diimplementasikan tahapantahapan dari metode yang akan menjadi hasil penelitian yaitu sebagai berikut :

\section{Menentukan Kriteria dan Bobot}

Pada penelitian ini, kriteria dari cabai yang akan diproses sebagai berikut :

Tabel 1. Kriteria dan Bobot

\begin{tabular}{|c|c|c|}
\hline Kriteria & Keterangan & Bobot \\
\hline C1 & Masa Panen & 0,25 \\
\hline C2 & Hasil Panen & 0,3 \\
\hline C3 & Berat Buah & 0,2 \\
\hline C4 & Panjang Buah & 0,15 \\
\hline C5 & Ketahanan Hama & 0,1 \\
\hline
\end{tabular}

\section{Menentukan Alternatif}

Adapun alternatif dari cabai yaitu sebagai berikut :

Tabel 2. Alternatif

\begin{tabular}{|c|c|}
\hline Alternatif & Keterangan \\
\hline A1 & Cabai Rawit \\
\hline A2 & Cabai Laba \\
\hline A3 & Cabai Merah Besar \\
\hline A4 & Cabai Taro \\
\hline A5 & Cabai Arimbi \\
\hline
\end{tabular}

\section{Menentukan nilai alternatif dan kriteria (Rating Kecocokan)}

Rating kecocokan adalah nilai dari masing-masing alternatif terhadap masingmasing dari kriteria yang ada dalam penelitian dan diambil dari sampel yang diberikan oleh Dinas Pertanian Kota Tanjungbalai.

Tabel 3. Rating Kecocokan

\begin{tabular}{|c|c|c|c|c|c|c|}
\hline No & Alternatif & C1 & C2 & C3 & C4 & C5 \\
\hline 1 & A1 & 5 & 4 & 4 & 3 & 3 \\
\hline 2 & A2 & 4 & 4 & 3 & 4 & 3 \\
\hline 3 & A3 & 3 & 5 & 4 & 4 & 4 \\
\hline 4 & A4 & 4 & 3 & 3 & 4 & 3 \\
\hline 5 & A5 & 5 & 3 & 4 & 5 & 4 \\
\hline
\end{tabular}


Vol. 1 No. 2, Juni 2021, hlm. $187-194$

DOI: https://doi.org/10.33330/jutsi.v2i1.1179

Available online at http://jurnal.stmikroyal.ac.id/index.php/jutsi

\section{Perhitungan matriks normalisasi}

Adapun proses perhitungan matriks normalisasi berasal dari masing-masing kriteria dibagi akar semua kriteria dikuadratkan 2 dan ditambah semua kuadrat tersebut. Adapun perhitungan tersebut sebagai berikut.

$$
\begin{aligned}
& \text { Perhitungan dari A1-A5 ke Semua C1 } \\
& \begin{array}{l}
\text { A1 ke } C 1=\frac{5}{\sqrt{5^{2}+4^{2}+3^{2}+4^{2}+5^{2}}}=0,524 \\
\text { A2 ke } C 1=\frac{4}{\sqrt{5^{2}+4^{2}+3^{2}+4^{2}+5^{2}}}=0,419 \\
\text { A3 ke } C 1=\frac{3}{\sqrt{5^{2}+4^{2}+3^{2}+4^{2}+5^{2}}}=0,314 \\
\text { A4 ke } C 1=\frac{4}{\sqrt{5^{2}+4^{2}+3^{2}+4^{2}+5^{2}}}=0,419 \\
\text { A5 ke } C 1=\frac{5}{\sqrt{5^{2}+4^{2}+3^{2}+4^{2}+5^{2}}}=0,524
\end{array}
\end{aligned}
$$

Perhitungan dari A1-A5 ke Semua C2

$$
\begin{aligned}
& \text { A1 ke } C 2=\frac{4}{\sqrt{4^{2}+4^{2}+5^{2}+3^{2}+3^{2}}}=0,462 \\
& \text { A2 ke } C 2=\frac{4}{\sqrt{4^{2}+4^{2}+5^{2}+3^{2}+3^{2}}}=0,462 \\
& \text { A3 ke } C 2=\frac{5}{\sqrt{4^{2}+4^{2}+5^{2}+3^{2}+3^{2}}}=0,577 \\
& \text { A4 ke } C 2=\frac{3}{\sqrt{4^{2}+4^{2}+5^{2}+3^{2}+3^{2}}}=0,346 \\
& \text { A5 ke } C 2=\frac{3}{\sqrt{4^{2}+4^{2}+5^{2}+3^{2}+3^{2}}}=0,346
\end{aligned}
$$

Perhitungan dari A1-A5 ke Semua C3

$$
\begin{aligned}
& \text { A1 ke } C 3=\frac{4}{\sqrt{4^{2}+3^{2}+4^{2}+3^{2}+4^{2}}}=0,492 \\
& \text { A2 ke } C 3=\frac{3}{\sqrt{4^{2}+3^{2}+4^{2}+3^{2}+4^{2}}}=0,369 \\
& \text { A3 ke } C 3=\frac{4}{\sqrt{4^{2}+3^{2}+4^{2}+3^{2}+4^{2}}}=0,492 \\
& \text { A4 ke } C 3=\frac{3}{\sqrt{4^{2}+3^{2}+4^{2}+3^{2}+4^{2}}}=0,369 \\
& \text { A5 ke } C 3=\frac{4}{\sqrt{4^{2}+3^{2}+4^{2}+3^{2}+4^{2}}}=0,492
\end{aligned}
$$


Vol. 1 No. 2, Juni 2021, hlm. $187-194$

DOI: https://doi.org/10.33330/jutsi.v2i1.1179

Available online at http://jurnal.stmikroyal.ac.id/index.php/jutsi

Perhitungan dari A1-A5 ke Semua C4

$A 1$ ke $C 4=\frac{3}{\sqrt{3^{2}+4^{2}+4^{2}+4^{2}+5^{2}}}=0,331$

A2 ke $C 4=\frac{4}{\sqrt{3^{2}+4^{2}+4^{2}+4^{2}+5^{2}}}=0,442$

A3 ke $C 4=\frac{4}{\sqrt{3^{2}+4^{2}+4^{2}+4^{2}+5^{2}}}=0,442$

A4 ke $C 4=\frac{4}{\sqrt{3^{2}+4^{2}+4^{2}+4^{2}+5^{2}}}=0,442$

A5 ke $C 4=\frac{5}{\sqrt{3^{2}+4^{2}+4^{2}+4^{2}+5^{2}}}=0,552$

Perhitungan dari A1-A5 ke Semua C5

A1 ke $C 5=\frac{3}{\sqrt{3^{2}+3^{2}+4^{2}+3^{2}+4^{2}}}=0,391$

A2 ke $C 5=\frac{3}{\sqrt{3^{2}+3^{2}+4^{2}+3^{2}+4^{2}}}=0,391$

A3 ke $C 5=\frac{4}{\sqrt{3^{2}+3^{2}+4^{2}+3^{2}+4^{2}}}=0,521$

A4 ke $C 5=\frac{3}{\sqrt{3^{2}+3^{2}+4^{2}+3^{2}+4^{2}}}=0,391$

A5 ke $C 5=\frac{3}{\sqrt{3^{2}+3^{2}+4^{2}+3^{2}+4^{2}}}=0,521$

Maka dari perhitungan di atas, didapat matrik normalisasi digambarkan pada tabel berikut :

Tabel 4. Matriks Normalisasi

\begin{tabular}{|c|c|c|c|c|c|c|}
\hline No & Alternatif & C1 & C2 & C3 & C4 & C5 \\
\hline 1 & A1 & 0,524 & 0,462 & 0,492 & 0,331 & 0,391 \\
\hline 2 & A2 & 0,419 & 0,462 & 0,369 & 0,442 & 0,391 \\
\hline 3 & A3 & 0,314 & 0,577 & 0,492 & 0,442 & 0,521 \\
\hline 4 & A4 & 0,419 & 0,346 & 0,369 & 0,442 & 0,391 \\
\hline 5 & A5 & 0,524 & 0,346 & 0,492 & 0,552 & 0,521 \\
\hline
\end{tabular}

\section{Perhitungan alternatif dari semua kriteria dan bobot}

Dalam perhitungan ini, masing-masing alternatif dan setiap kriterianya di kali dengan masing-masing bobot dari kriteria. Adapun perhitungan tersebut sebagai berikut

$$
\begin{aligned}
\mathrm{A} 1 & =(0,524 \times 0,25)+(0,462 \times 0,30)+(0,492 \times 0,20)+(0,331 \times 0,15)+(0,391 \times 0,10) \\
& =0,457
\end{aligned}
$$


Vol. 1 No. 2, Juni 2021, hlm. $187-194$

DOI: https://doi.org/10.33330/jutsi.v2i1.1179

Available online at http://jurnal.stmikroyal.ac.id/index.php/jutsi

$$
\begin{aligned}
\mathrm{A} 2 & =(0,419 \times 0,25)+(0,462 \times 0,30)+(0,369 \times 0,20)+(0,442 \times 0,15)+(0,391 \times 0,10) \\
& =0,432 \\
\mathrm{~A} 3 & =(0,314 \times 0,25)+(0,577 \times 0,30)+(0,492 \times 0,20)+(0,442 \times 0,15)+(0,521 \times 0,10) \\
& =0,469 \\
\text { A4 } & =(0,419 \times 0,25)+(0,346 \times 0,30)+(0,369 \times 0,20)+(0,442 \times 0,15)+(0,391 \times 0,10) \\
& =0,388 \\
\text { A5 } & =(0,524 \times 0,25)+(0,346 \times 0,30)+(0,492 \times 0,20)+(0,552 \times 0,15)+(0,521 \times 0,10) \\
& =0,468
\end{aligned}
$$

Maka dari hasil perhitungan akhir di atas, akan disatukan menjadi tabel dibawah ini dengan hasil perankingannya.

Tabel 5. Hasil Akhir dan Perankingan

\begin{tabular}{|c|c|c|c|}
\hline No & Alternatif & Hasil & Ranking \\
\hline 1 & A1 & 0,457 & 3 \\
\hline 2 & A2 & 0,423 & 4 \\
\hline 3 & A3 & 0,469 & 1 \\
\hline 4 & A4 & 0,388 & 5 \\
\hline 5 & A5 & 0,468 & 2 \\
\hline
\end{tabular}

Dari hasil perhitungan di atas, maka yang menjadi rekomendasi bibit cabai unggul adalah cabai merah besar dengan hasil 0,469.

\section{SIMPULAN}

Dari hasil penelitian ini, kriteria-kriteria yang berhasil diterapkan dalam penelitian ini adalah masa panen, hasil panen, berat buah, panjang buah dan ketahanan hama. Sedangkan yang menjadi alternatif cabai ini adalah cabai rawit, cabai laba, cabai merah besar, cabai taro dan cabai arimbi. Implementasi Metode MOORA dalam pemilihan bibit cabai unggul yang telah dilakukan, mendapatkan hasil cabai yang paling unggul dengan nilai tertinggi 0,469 yaitu cabai merah besar. Maka yang menjadi hasil rekomendasi implementasi Metode MOORA ini adalah cabai merah besar.

\section{DAFTAR PUSTAKA}

[1] S. Andriyani and F. M. Yuma, "KOMBINASI METODE ANALITICAL HIERARCHY PROCESS DAN WEIGHTED PRODUCT DALAM PENENTUAN BENIH CABAI UNGGUL Sistem Informasi, Sekolah Tinggi Manajemen Infromatika dan Komputer Royal PENDAHULUAN Cabai ( Capsicum annuum L ) tumbuhan yang merupakan sebuah komodit," vol. 6, no. 2, pp. 117-124, 2020. 
Vol. 1 No. 2, Juni 2021, hlm. $187-194$

DOI: https://doi.org/10.33330/jutsi.v2i1.1179

Available online at http://jurnal.stmikroyal.ac.id/index.php/jutsi

[2] A. Y. Saputra and P. Yogi, "Penerapan Metode MOORA Dalam Pemilihan Sekolah Dasar," Sist. J. Sist. Inf., vol. 8, no. 2, pp. 305-312, 2019, [Online]. Available: http://sistemasi.ftik.unisi.ac.id/index.php/stmsi/article/view/454.

[3] E. Sofiah, "Sistem Pendukung Keputusan," Sist. Pendukung Keputusan, vol. 8, pp. 1-7, 2014.

[4] A. Afrisawati and S. Sahren, "Analisis Perbandingan Menggunakan Metode Moora Dan Waspas Pemilihan Bibit Sapi Potong Terbaik," JURTEKSI (Jurnal Teknol. dan Sist. Informasi), vol. 6, no. 3, pp. 269-276, 2020, doi: 10.33330/jurteksi.v6i3.827.

[5] I. Hidayatulloh and M. Z. Naf'an, "Metode Moora Dengan Pendekatan PriceQuality Ratio Untuk Rekomendasi Pemilihan Smartphone," J. SINTAK, no. November, pp. 62-68, 2017. 